\title{
REVIEW
}

\section{Probiotics to counteract biofilm-associated infections: promising and conflicting data}

\author{
Claudia Vuotto, Francesca Longo and Gianfranco Donelli
}

Altered bowel flora is currently thought to play a role in a variety of disease conditions, and the use of Bifidobacterium spp. and Lactobacillus spp. as probiotics has been demonstrated to be health-promoting, even if the success of their administration depends on the applied bacterial strain(s) and the targeted disease. In the last few decades, specific probiotics have been shown to be effective in the treatment or the prevention of acute viral gastroenteritis, pediatric post-antibiotic-associated diarrhea, some pediatric allergic disorders, necrotizing enterocolitis in preterm infants, inflammatory bowel diseases and postsurgical pouchitis. The potential application of probiotics is continuously widening, with new evidence accumulating to support their effect on the prevention and treatment of other disease conditions, including several oral diseases, such as dental caries, periodontal diseases and oral malodor, as well as genitourinary and wound infections. Considering the increasingly widespread ability of pathogens to generate persistent biofilm-related infections, an even more attractive proposal is to administer probiotics to prevent or counteract biofilm development. The response of biofilm-based oral, intestinal, vaginal and wound infections to probiotics treatment will be reviewed here in light of the most recent results obtained in this field.

International Journal of Oral Science (2014) 6, 189-194; doi:10.1038/ijos.2014.52; published 26 September 2014

Keywords: biofilm; genitourinary tract; gut; infections; oral cavity; probiotics; wounds

\section{INTRODUCTION}

A role of some intestinal bacteria to maintain or restore health conditions was firstly proposed by Elie Metchnikoff more than one century ago when he observed that 'good' lactic acid-producing bacteria, particularly those belonging to the genera Bifidobacterium and Lactobacillus, were beneficial to the host by reducing the growth of toxigenic bacteria within the colon. ${ }^{1-2}$

The original bowel toxemia theory evolved in the following decades into the intestinal dysbiosis hypothesis, with the term 'dysbiosis' being defined as '...qualitative and quantitative changes in the intestinal flora, their metabolic activity and their local distribution'. ${ }^{3}$

Altered bowel flora is currently believed to play a role not only in intestinal disorders but also in a variety of disease conditions. ${ }^{4}$ The use of Bifidobacterium spp. and Lactobacillus spp. as probiotics, with this term being defined by the Food and Agriculture Organization of the United Nations (FAO) and the World Health Organization (WHO) as 'live microorganisms which when administered in adequate amounts confer a health benefit on the host', ${ }^{5}$ has been demonstrated to be health-promoting, even if the success of specific probiotics depends on the applied bacterial strain(s), the number of species, the microbial concentration and the targeted disease. ${ }^{6-8}$

In fact, according to the Cochrane Summaries, ${ }^{9}$ probiotics have been shown to be effective or possibly effective in the treatment or prevention of acute viral gastroenteritis, ${ }^{10}$ pediatric post-antibioticassociated diarrhea, ${ }^{11}$ certain pediatric allergic disorders, ${ }^{12}$ necrotizing enterocolitis in preterm infants, ${ }^{13}$ inflammatory bowel diseases ${ }^{14}$ and post-surgical pouchitis. ${ }^{15}$

In the post-genomic era, high-throughput methodologies, such as metagenomics, transcriptomics, proteomics and metabolomics, have greatly helped to classify strains as probiotics ${ }^{16}$ and to understand the mechanisms by which several lactic acid-producing bacteria help to maintain human health and the numerous functions assigned to these species in the gut. ${ }^{17}$ They provide nutrients, help the host to digest foods, compete for space and nutrients with potential pathogens and induce the secretion of antimicrobial peptides through an interaction with intestinal epithelial cells. ${ }^{18-19}$

Bifidobacteria and Lactobacilli are also able to stimulate the development of the immune system, with certain species of gut commensal microbiota being required for immune regulation and tolerance of the large amount of antigens present in the gut. ${ }^{20-21}$ Perturbations in the microbiota could result in a lack of immune regulation, outgrowth of more pathogenic microbes and promotion of tissue inflammation.

The potential application of probiotics is continuously widening, with new evidence supporting their effect on the prevention and treatment of other disease conditions, including urogenital infections, ${ }^{22}$ cystic fibrosis $^{23}$ and various cancers. ${ }^{24-25}$

With regard to oral health, great attention is being given to the use of a probiotic therapy for the treatment of dental caries, periodontal diseases and oral malodor. ${ }^{26-27}$ 
With this in mind, recent data provide proof-of-concept that a mixture of streptococcal species applied to canine teeth as an adjunctive therapy ${ }^{28}$ along with the probiotic Lactobacillus brevis CD2 (refs. 29-30) can delay the recolonization of periodontal pathogens and reduce inflammation through modulatory effects on the host response and on the periodontal microbiota.

Furthermore, the use of a mouth rinse containing Bacillus subtilis ${ }^{31}$ or the oral administration of tablets containing Lactobacillus salivarius $^{32}$ reduced the number of periodontal pathogens. While this approach seems promising, it is still a relatively new concept, and more research is needed to determine its clinical efficacy.

Considering the increasingly widespread ability of pathogens to generate persistent biofilm-related infections, ${ }^{33}$ an even more attractive proposal is to administer probiotics to prevent or counteract biofilm development. ${ }^{34}$

In fact, in vitro investigations on adhesion, bacteriocin production, co-aggregation, growth inhibition and metabolic activity have suggested a potential role of probiotic Lactobacilli and Bifidobacteria in modulating the microbial ecology of biofilms, in particular, those developing at the oral, intestinal, vaginal and wound level.

The ability to adhere to mucus and epithelial cells, as well as to coaggregate, is proposed as one of the most important selection criteria for potential probiotic strains. ${ }^{35-39}$ Biofilm-growing probiotic strains have the ability to contribute to enhanced thermotolerance and freeze-drying resistance, ${ }^{40}$ and to replace resident biofilm-growing pathogens with a non-pathogenic bacteriocin-producing variant. ${ }^{41-43}$

Despite this, the molecular mechanisms controlling biofilm development of probiotic bacteria have so far been poorly investigated, ${ }^{44-45}$ when compared with the extensive studies performed on the biofilm formation of several microbial pathogens. In fact, these types of studies could provide important insights into how normal microbiota is maintained, as well as being key starting points for the rational use of probiotics.

The response to probiotics treatment of biofilm-based oral, intestinal, vaginal and wound infections is reviewed here.

\section{COMPETITION AND INTERFERENCE OF PROBIOTICS WITH ORAL BIOFILMS}

Dental plaque, as a well-defined multispecies biofilm constituted by a complex microbial community, is known to play a major role in a variety of dental diseases, such as dental caries and periodontal disease. In the healthy oral cavity, beneficial and pathogenic bacteria maintain a delicate balance, while the accumulation of strictly anaerobic Gramnegative bacteria within the biofilm and the resulting microbial imbalance predispose one to the onset of periodontal diseases and transform the dental plaque into a difficult to treat 'pathogenic' biofilm. ${ }^{46}$

Thus, oral cavities have been suggested as a relevant target for probiotic applications, through the use of non-pathogenic, bacteriocinproducing Lactobacilli and Bifidobacteria to restore the microbial balance and to counteract pathogenic bacteria. ${ }^{47-48}$

Clinical trials have been carried out to evaluate the ability of different probiotic products to reduce dental caries and caries risk in children, ${ }^{49-51}$ young adults ${ }^{52}$ and healthy complete denture wearers. ${ }^{53}$

In particular, after recognizing biofilms as the major cause of oral diseases, the extra-intestinal effect of probiotic strains through both specific interactions with dental biofilm and influencing oral health have been recently investigated. ${ }^{54-55}$

Several studies detailing the role of probiotics in preventing dental caries have been published, with a particular emphasis on their ability to co-aggregate with caries-associated strains ${ }^{56-57}$ and to reduce the number of cariogenic bacteria, especially Streptococcus mutans, within the dental plaque.

In 2002, Comelli and co-workers ${ }^{58}$ encouraged the selection of nonpathogenic dairy bacterial strains that were able to decrease the cariogenic potential of dental plaque. Specifically, they found that Lactococcus lactis NCC2211 was able to successfully incorporate itself into a biofilm, thus mimicking the dental plaque, and was able to modulate the growth of the cariogenic Streptococcus sobrinus OMZ176.

Afterwards, the oral bacterium S11, isolated from the saliva of young children without dental caries and with a $99.5 \%$ similarity with Lactobacillus fermentum, was demonstrated to inhibit the ability of $S$. mutans Ingbritt, a laboratory reference strain, to adhere on cuvette walls and to synthesize extracellular glucans. ${ }^{59}$

More specifically, an L. fermentum-derived biosurfactant was demonstrated to greatly reduce the ability of $S$. mutans to produce sucrose using glucosyltransferases (GTs) and to grow as biofilm, thus having an anti-biofouling effect. ${ }^{60}$

In recent years, the ability of other commonly used probiotic strains (Lactobacillus acidophilus DSM 20079, Lactobacillus paracasei DSMZ 16671, Lactobacillus plantarum 299v, Lactobacillus rhamnosus GG, Lactobacillus reuteri strains PTA 5289 and L. reuteri SD2112, etc.) to hamper $S$. mutans growth and biofilm formation in vitro has been evaluated, and these results suggest that the antimicrobial activity of Lactobacilli seems to be strain-specific and pH-dependent. ${ }^{61-62}$ Lactobacilli have also been reported to reduce streptococcal adhesion, ${ }^{63}$ not as much on glass surfaces, but in particular on saliva-coated hydroxyapatite. ${ }^{64}$

On the other hand, probiotic species were also shown to possibly be cariogenic themselves under specific growth conditions (low $\mathrm{pH}$ and concurrent inoculation with the microcosm). For instance, intestinal probiotic $L$. salivarius W24 was able to affect the compositional stability of the microbial communities derived from individual saliva and appeared to have a cariogenic potential. ${ }^{65}$ Furthermore, Schwendicke and co-workers ${ }^{66}$ compared to and combined with S. mutans (SM), the probiotic L. rhamnosus GG (LGG), by simulating three biofilm compositions (SM, LGG, SM $\times$ LGG) and two dental lesion sites (smooth enamel, dentin cavity). The resulting mineral loss $(\Delta Z)$ in dental tissues and bacterial numbers measured after 10 days showed that this probiotic, other than lacking the inhibitory effects on SM, also induced mineral loss especially in dentin cavities and under highly cariogenic conditions, thus contributing to the caries process in a dental biofilm model.

Even if the strong evidence supporting the efficacy of probiotic strains in counteracting gingivitis and periodontitis is still not convincing, data in the literature are also accumulating with regards to this issue.

In general, several papers state that probiotics could be useful in the improvement/maintenance of oral health, mostly in subjects at a high risk of periodontal disease. In in vitro studies and clinical trials, a variation in the composition of oral lactoflora in chronic periodontitis or gingivitis and in healthy subjects has been proposed, with both homo- and heterofermentative oral Lactobacilli suppressing the growth of oral pathogens. ${ }^{67-72}$

However, these results are all strain-, species- and origin-specific, and the effectiveness of probiotics on the prevention and treatment of periodontal diseases is therefore questionable. Currently, there is scarce evidence about the possible benefits of a systematic preventive use of probiotics in patients affected by periodontal diseases. ${ }^{73}$

Regarding the ability of probiotic strains to interfere with biofilmgrowing periodontal pathogens, the experimental results to date are few and divergent.

In fact, Teanpaisan and co-workers ${ }^{55}$ as well as Vuotto and coworkers ${ }^{74}$ have recently shown that Lactobacillus SD1-SD6 and L. brevis 


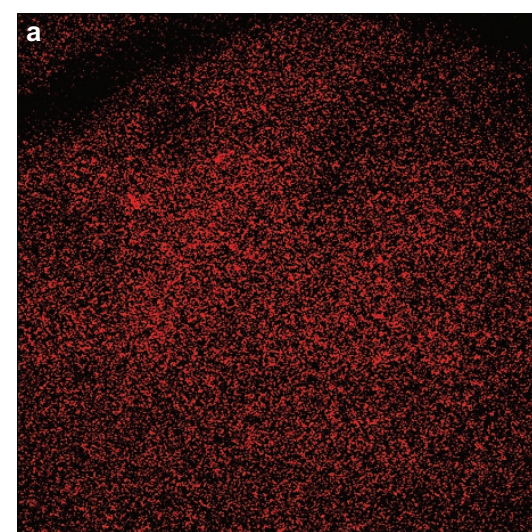

Lactobacillus brevis

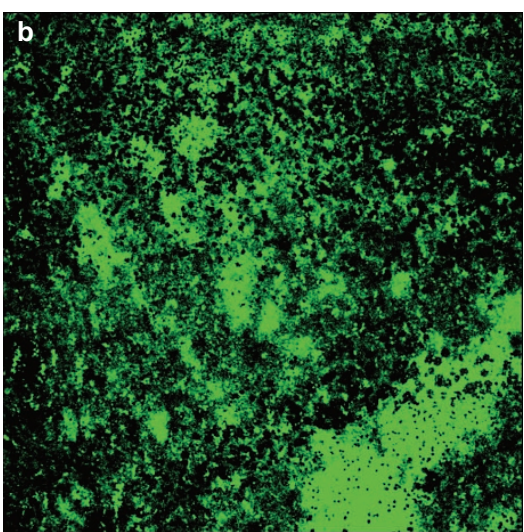

Prevotella melaninogenica

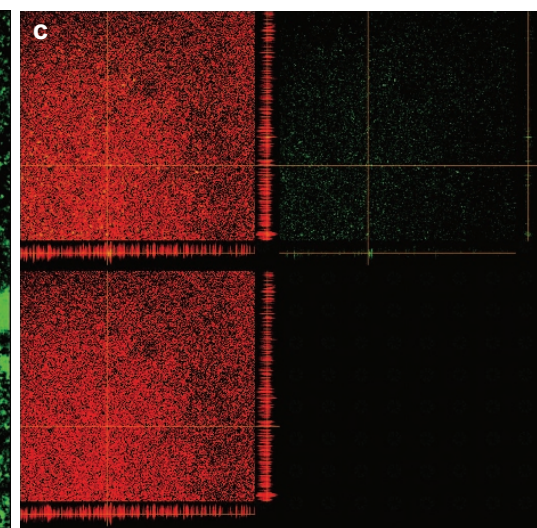

L. brevis + P. melaninogenica

Figure 1 Confocal laser scanning microscopy images of $L$. brevis CD2 and $P$. melaninogenica PM1 strains. (a, b) Strains growing as single species biofilms; (c) a $24 \mathrm{~h}$ mixed biofilm formed by both strains: in the upper left a superimposition of the images of $P$. melaninogenica PM1 biofilm (upper right) and of $L$. brevis CD2 biofilm (lower left) is shown.

CD2, respectively, exhibited a strong inhibitory effect against Gramnegative periodontal pathogens, in the first case Porphyromonas gingivalis and Aggregatibacter actinomycetemcomitans and in the latter Prevotella melaninogenica (Figure 1). Twetman group reported that a daily intake of probiotic lozenges did not seem to significantly affect plaque accumulation, inflammatory reaction or biofilm composition during experimental gingivitis. ${ }^{75}$

Conflicting results suggesting that probiotic therapy can prevent or combat oral disease is just beginning to evolve, and it is likely that other factors, such as the site of lesion or the availability of fermentable carbohydrates, might also affect caries, in some case more significantly than the bacterial composition of the oral cavity. ${ }^{76}$

\section{COMPETITION AND INTERFERENCE OF PROBIOTICS WITH INTESTINAL BIOFILM}

The most claimed use of probiotics is in contribute to intestinal wellbeing. In fact, administered probiotics appear to be able, although only transiently for the duration of their administration, to influence the composition and function of the intestinal microbiota, ${ }^{77}$ therefore providing robust clinical data on the benefits of probiotics in at least 3 main areas: intestinal infection, inflammatory bowel disease and irritable bowel syndrome. $^{78}$

Probiotic cocktails of different strains have also been demonstrated to be useful in some gastrointestinal diseases. For instance, VSL\#3, a cocktail containing 8 different strains, has proven to be effective in the primary prevention ${ }^{79}$ and maintenance of remission ${ }^{80}$ among patients with pouchitis.

The anti-biofilm properties of some probiotics against biofilmgrowing enteropathogens have also been evaluated, despite the fact that the results obtained so far are few and conflicting. On the one hand, there are studies reporting that probiotics are able to inhibit biofilm formation of intestinal pathogens, but on the other hand different experimental data seem to support the enhancing of enteropathogens biofilm biomass in the presence of probiotics.

In the first case, Collado and colleagues showed that specific probiotic combinations are able to enhance the inhibition percentages of pathogens adhering to intestinal mucus when compared to single probiotic strains. ${ }^{81}$ Furthermore, single strains (L. acidophilus Bar13, L. plantarum Bar10, Bifidobacterium longum Bar33 and B. lactis Bar30) were effective in displacing the enteropathogens Salmonella typhimurium and Escherichia coli $\mathrm{H} 10407$ from a Caco-2 cell layer, ${ }^{82}$ and the exopolysaccharides released from L. acidophilus A4 were able to drastically decrease enterohemorrhagic E. coli biofilms on 96-well microplates $(87 \%)$ and on polystyrene and polyvinyl chloride surfaces ( $94 \%)$ by affecting genes related to curli production ( $c r l, c s g A$ and $\operatorname{csg} B$ ) and chemotaxis $(\operatorname{cheY}) .{ }^{83}$ In 2010, Hancock and coworkers investigated the biofilm-forming capacity of Nissle 1917 and found that this strain was a significantly better biofilm former than enteropathogenic, enterotoxigenic and enterohaemorrhagic E. coli strains, with the exception of being able to outcompete such strains during biofilm formation. ${ }^{84}$

On the other hand, exopolysaccharides fractions produced by three probiotic strains (L. rhamnosus GG, B. longum NB667, and Bifidobacterium animalis IPLA-R1) have been demonstrated to increase the adhesion of Enterobacter sakazakii ATCC 29544 and E. coli NCTC 8603, Salmonella enterica serovar Typhimurium ATCC 29631 and Clostridium difficile ATCC 9689, ${ }^{85}$ while Miyazaki and co-workers ${ }^{86}$ reported in 2010 on the effects of nine probiotic bacterial strains on the growth, adhesion, and biofilm formation of enteroaggregative E. coli (EAggEC), with the supernatants of L. casei ss. casei and L. casei ss. rhamnosus stimulating biofilm formation of EAggEC.

\section{COMPETITION AND INTERFERENCE OF PROBIOTICS WITH BIOFILMS OF GENITOURINARY TRACT}

Lactobacilli inhabiting the genitourinary environment seem to play a pivotal role in preventing illnesses, including urinary tract infections $^{87-92}$ and bacterial vaginosis (BV), that is one the most common vaginal infections in women. ${ }^{93-102}$

Even at a small level, several clinical studies have demonstrated the potential of probiotics to treat $\mathrm{BV}$, with three of four studies reporting a significant cure rate, ${ }^{103-105}$ and three of five studies describing reduced recurrence rates when probiotics were used following antibiotic treatment. ${ }^{106-108}$

Most of these clinical trials were performed using high doses of Lactobacilli, thus suggesting that the amount of Lactobacilli could have a role in the effectiveness of the probiotic product. ${ }^{22}$

In particular, there is considerable evidence supporting the notion that hydrogen peroxide $\left(\mathrm{H}_{2} \mathrm{O}_{2}\right)$ production by Lactobacilli is a key factor in resisting $\mathrm{BV}$, and these particular strains are found in $61 \%$ of pregnant women with normal flora, yet in only $5 \%$ of women with BV. ${ }^{109}$ In fact, in vitro studies demonstrated that $\mathrm{H}_{2} \mathrm{O}_{2}$ is toxic to 
BV-causative organisms, such as Gardnerella vaginalis, Prevotella bivia and Atopobium vaginae. ${ }^{110}$

Furthermore, the ability of Lactobacilli to co-aggregate with some urinary pathogens allows them to block the ability of pathogens to adhere and kills the pathogens through the production of antimicrobial substances. ${ }^{111-112}$ As an example, Mastromarino et al. ${ }^{113}$ found that Lactobacillus gasseri 335 and L. salivarius FV2 were able to coaggregate with $G$. vaginalis, and the combination of these lactobacilli strains with $L$. brevis $\mathrm{CD} 2$ in a vaginal tablet reduced the $G$. vaginalis adhesion by $57.7 \%$.

It was demonstrated that $G$. vaginalis forms a biofilm on the vaginal epithelium that is highly tolerant to antibiotics. ${ }^{114-115}$ Biofilm formation, among other factors, allows for G. vaginalis to survive in the presence of lactobacilli-derived $\mathrm{H}_{2} \mathrm{O}_{2}$ and lactic acid. ${ }^{116}$

Despite this, recent experiments suggest that probiotics may still have a place in the treatment of BV alone or in combination with antibiotic therapy. ${ }^{117-118}$

Additionally, probiotics that produce low amounts of $\mathrm{H}_{2} \mathrm{O}_{2}$, such as L. reuteri $\mathrm{RC}-14$, are able to largely displace G. vaginalis, and deconvolution microscopy shows changes in the structure and viability of the biofilms, with loss of dense G. vaginalis biofilm pods. ${ }^{119}$

With regard to the ability of specific probiotics to enhance the antibiotic activity against $G$. vaginalis biofilm, McMillan and colleagues ${ }^{120}$ evaluated changes occurring in a 12 -mm-thick confluent $A$. vaginae and $G$. vaginalis biofilm after antibiotic and probiotic treatment. Metronidazole produced holes within the biofilm without eradicating bacteria, while L. reuteri RC-14 and L. rhamnosus GR-1 infiltrated BV biofilms leading to a higher bacterial cell death.

Recently, four single probiotics and four probiotic mixtures have been tested for their inhibitory activity against the urinary pathogens E. coli NCTC 9001 and Enterococcus faecalis NCTC 00775, a greater effect of the probiotic mixtures with respect to the single strains being not detected. ${ }^{121}$

Lately, other probiotic species have been shown to positively impact vaginal infections, with in vitro results providing a basis for the use of Pediococcus pentosaceus SB83 as a vaginal probiotic to prevent Listeria monocytogenes colonization in pregnant women. ${ }^{122}$

All of these findings provided evidence of how probiotics could interfere with an aberrant vaginal microbiota and gave strength to the possibility to eradicate pathogenic biofilms by administering probiotics, alone or combination with antimicrobials.

\section{COMPETITION AND INTERFERENCE OF PROBIOTICS WITH WOUNDS BIOFILM}

Recent findings indicate that chronic wound pathology may be caused by alterations in skin microbiota. Thus, probiotics could be promising tools to topically prevent and treat non-healing wounds. ${ }^{123}$

Nevertheless, very little data, although consistent, have been reported to date on the ability of probiotic strains to prevent wound infections by acting against the main biofilm-growing causative agents. In fact, the research in this field is really in its infancy.

First, Valdéz and colleagues evaluated the ability of the probiotic organism L. plantarum to inhibit the pathogenic activity of Pseudomonas aeruginosa, demonstrating that probiotic whole cultures as well as culture filtrates (acid filtrate and neutralized acid filtrate) were able to in vitro inhibit $P$. aeruginosa elastase and biofilm by affecting the production of the quorum-sensing signal molecules, acyl-homoserine-lactones. A burnedmouse model was used to test the in vivo activity of L. plantarum at 3, 4, 5, 7 and 9 days post-infection with $P$. aeruginosa; inhibition of $P$. aeruginosa colonization after 5,10 and 15 days was proven by analyzing samples from skin, liver and spleen. These results revealed that L. plantarum and/or its metabolites could be considered as potential therapeutic agents for the local treatment of $P$. aeruginosa burn infections. ${ }^{124}$

Following these results, only a few other papers have been published in this area, specifically by in vitro studing of the two bacterial species mainly involved in biofilm-based wound infections, i.e., Staphylococcus aureus and $P$. aeruginosa. Walencka et al. ${ }^{125}$ evaluated the effects of surfactants obtained from three L. acidophilus strains on $S$. aureus and Staphylococcus epidermidis adhesion and biofilm formation and demonstrated that both species, even if to a different extent, were inhibited by the tested surfactants. In particular, the probiotic-derived surfactants reduced the bacterial deposition rate and biofilm development without affecting cell growth, most likely by influencing the staphylococcal cell surface hydrophobicity. Furthermore, Sadowska and coworkers observed a limitation of staphylococcal biofilm formation using cell-free supernatants of $L$. acidophilus $\mathrm{H}-1$ and a direct competitive interactions between $S$. aureus strains and the probiotic strain. ${ }^{126}$

The inhibition of $S$. aureus and $P$. aeruginosa growth and biofilm formation was also evaluated by a co-incubation with $L$. fermentum or culture filtrate of L. fermentum. These results showed that L. fermentum-secreted compound(s) inhibited both growth and biofilm formation of several $S$. aureus and $P$. aeruginosa strains. ${ }^{127}$ Finally, $L$. plantarum has been demonstrated to be topically effective in preventing skin wound infections in mice, ${ }^{128}$ not only against $P$. aeruginosa ${ }^{124}$ but also against $S$. aureus.

\section{CONCLUSIONS}

The increasing interest in promoting health in a natural way has intensified the research in the field of probiotic on a global scale over the last two decades, thus leading to the industrial production of an overwhelming number of new products with an estimated $7 \%$ annual growth (Global Industry Analysis Report 2012).

To date, clinical confirmations have been obtained on the relevance of the relationship between immune system and probiotic microorganisms in protecting the host from colonization by pathogenic species. In fact, probiotics produce a variety of substances, ranging from relatively nonspecific fatty acids and peroxides to highly specific bacteriocins, which have been widely demonstrated to inhibit or kill other potentially pathogenic bacteria.

In vitro studies and clinical trials have accumulated evidence in the recent years on the effect of probiotics, especially Lactobacilli, in oral, wound and vaginal infections through a competition and counteraction of pathogens. However, data are still scarce and not always consistent to look at probiotics as tool to avoid biofilm formation and/or to disperse pre-formed pathogenic biofilms.

However, conflicting results also arise from a confounding interpretation of available data, often due not only to the differences in dose, delivery vehicle and evaluation of viability and efficacy, but especially to the variability in strain selection. In fact, no two probiotics are the same and, even within the same species, different strains may have quite different and sometimes contrasting effects.

In other words, an ideal probiotic that is able to compete and interfere with biofilm-growing pathogens needs to be properly identified, especially in the context of specific microbial targets and infection.

1 Metchnikoff E. Optimistic study//Mitchell PC ed. The prolongation of life. New York: G P Putnam's Sons, 1910: 96.

2 Podolsky S. Cultural divergence: Elie Metchnikoff's Bacillus bulgaricus therapy and his underlying concept of health. Bull Hist Med 1998; 72(1): 1-27.

3 Holzapfel WH, Haberer P, Snel J et al. Overview of gut flora and probiotics. Int J Food Microbiol 1998; 41(2): 85-101. 
4 Rajilić-Stojanović M. Function of the microbiota. Best Pract Res Clin Gastroenterol 2013; 27(1): 5-16.

5 World Health Organization. World Health Organization Report of a Joint FAO/WHO Expert Consultation of Evaluations of Health and Nutritional Properties of Probiotics in Food Including Powder Milk and Live Lactic Acid Bacteria. Geneva: World Health Organization, 2001

6 Ng SC, Hart AL, Kamm MA et al. Mechanisms of action of probiotics: recent advances. Inflamm Bowel Dis 2009; 15(2): 300-310.

7 Mikelsaar M, Lazar V, Onderdonk AB et al. Do probiotic preparations for humans really have efficacy? Microb Ecol Health Dis 2011, 22: 10128.

8 Bertazzoni E, Donelli G, Midtvedt T et al. Probiotics and clinical effects: is the number what counts? J Chemother 2013; 25(4): 193-212.

9 Podolsky SH. Metchnikoff and the microbiome. Lancet 2012; 380(9856): 1810-1811.

10 Guandalini S, Pensabene L, Zikri MA et al. Lactobacillus GG administered in oral rehydration solution to children with acute diarrhea: a multicenter European trial. $J$ Pediatr Gastroenterol Nutr 2000; 30(1): 54-60.

11 Johnston BC, Goldenberg JZ, Vandvik PO et al. Probiotics for the prevention of pediatric antibiotic-associated diarrhea. Cochrane Database Syst Rev 2011. (11): CD004827.

12 Marseglia GL, Tosca M, Cirillo I et al. Efficacy of Bacillus clausii spores in the prevention of recurrent respiratory infections in children: a pilot study. Ther Clin Risk Manag 2007; 3(1): 13-17.

13 Alfaleh K, Anabrees J, Bassler D et al. Probiotics for prevention of necrotizing enterocolitis in preterm infants. Cochrane Database Syst Rev 2011; (3): CD005496.

14 Chapman TM, Plosker GL, Figgitt DP. VSL\#3 probiotic mixture: a review of its use in chronic inflammatory bowel diseases. Drugs 2006. 66(10): 1371-1387.

15 Wall GC, Schirmer LL, Anliker LE et al. Pharmacotherapy for acute pouchitis. Ann Pharmacother 2011; 45(9): 1127-1137.

16 Donelli G, Vuotto C, Mastromarino P. Phenotyping and genotyping are both essential to identify and classify a probiotic microorganism. Microb Ecol Health Dis 2013; 24 10.3402/mehd.v24i0.20105.

17 Aires J, Butel MJ. Proteomics, human gut microbiota and probiotics. Expert Rev Proteomics 2011; 8(2): 279-288.

18 Louis P, O'Byrne CP. Life in the gut: microbial responses to stress in the gastrointestinal tract. Sci Prog 2010; 93(Pt 1): 7-36.

19 Kamada N, Chen GY, Inohara N et al. Control of pathogens and pathobionts by the gut microbiota. Nat Immunol 2013; 14(7): 685-690.

20 Ruemmele FM, Bier D, Marteau P et al. Clinical evidence for immunomodulatory effects of probiotic bacteria. J Pediatr Gastroenterol Nutr 2009; 48(2): 126-141.

21 Vieira AT, Teixeira MM, Martins FS. The role of probiotics and prebiotics in inducing gut immunity. Front Immunol 2013; 4: 445.

22 Mastromarino P, Vitali B, Mosca L. Bacterial vaginosis: a review on clinical trials with probiotics. New Microbiol 2013; 36(3): 229-238.

23 Alexandre Y, Le Blay G, Boisramé-Gastrin S et al. Probiotics: a new way to fight bacterial pulmonary infections? Med Mal Infect 2014; 44(1): 9-17.

24 Shida K, Nomoto K. Probiotics as efficient immunopotentiators: translational role in cancer prevention. Indian J Med Res 2013; 138(5): 808-814

25 Serban DE. Gastrointestinal cancers: influence of gut microbiota, probiotics and prebiotics. Cancer Lett 2014; 345(2): 258-270.

26 Saha S, Tomaro-Duchesneau C, Tabrizian M et al. Probiotics as oral health biotherapeutics. Expert Opin Biol Ther 2012; 12(9): 1207-1220.

27 Bizzini B, Pizzo G, Scapagnini G et al. Probiotics and oral health. Curr Pharm Des 2012; 18(34): 5522-5531.

28 Teughels W, Newman MG, Coucke W et al. Guiding periodontal pocket recolonization: a proof of concept. J Dent Res 2007; 86(11): 1078-1082.

29 Riccia DN, Bizzini F, Perilli MG et al. Anti-inflammatory effects of Lactobacillus brevis CD2) on periodontal disease. Oral Dis 2007; 13(4): 376-385.

30 Maekawa T, Hajishengallis G. Topical treatment with probiotic Lactobacillus brevis CD2 inhibits experimental periodontal inflammation and bone loss. J Periodontal Res 2014; doi: 10.1111/jre.12164. [Epub ahead of print].

31 Tsubura S, Mizunuma H, Ishikawa S et al. The effect of Bacillus subtilis mouth rinsing in patients with periodontitis. Eur J Clin Microbiol Infect Dis 2009; 28(11): 1353-1356.

32 Mayanagi G, Kimura M, Nakaya $S$ et al. Probiotic effects of orally administered Lactobacillus salivarius WB21-containing tablets on periodontopathic bacteria: double-blinded, placebo-controlled, randomized clinical trial. J Clin Periodontol 2009; 36(6): 506-513.

33 Grant SS, Hung DT. Persistent bacterial infections, antibiotic tolerance, and the oxidative stress response. Virulence 2013; 4(4): 273-283.

34 Longbottom C, Ekstrand K, Zero D et al. Novel preventive treatment options. Monog Oral Sci 2009; 21: 156-163.

35 Gopal PK, Prasad J, Smart J et al. In vitro adherence properties of Lactobacillus rhamnosus DR20 and Bifidobacterium lactis DR10 strains and their antagonistic activity against an enterotoxigenic Escherichia coli. Int J Food Microbiol 2001; 67(3): 207-216.

36 Kravtsov EG, Yermolayev AV, Anokhina IV et al. Adhesion characteristics of Lactobacillus is a criterion of the probiotic choice. Bull Exp Biol Med 2008; 145(2): 232-234.

37 Lasaro MA, Salinger N, Zhang J et al. F1C fimbriae play an important role in biofilm formation and intestinal colonization by the Escherichia colicommensal strain Nissle 1917. App/ Environ Microbiol 2009; 75(1): 246-251.

$38 \mathrm{Xu} \mathrm{H}$, Jeong HS, Lee HY et al. Assessment of cell surface properties and adhesion potential of selected probiotic strains. Lett App/ Microbiol 2009; 49(4): 434-442.

39 Lebeer S, Verhoeven TL, Claes IJ et al. FISH analysis of Lactobacillus biofilms in the gastrointestinal tract of different hosts. Lett Appl Microbiol 2011; 52(3): 220-226.
40 Cheow WS, Hadinoto K. Biofilm-like Lactobacillus rhamnosus probiotics encapsulated in alginate and carrageenan microcapsules exhibiting enhanced thermotolerance and freeze-drying resistance. Biomacromolecules 2013; 14(9): 3214-3222.

41 Jones SE, Versalovic J. Probiotic Lactobacillus reuteri biofilms produce antimicrobial and anti-inflammatory factors. BMC Microbiol 2009; 9: 35.

42 Samot J, Lebreton J, Badet C. Adherence capacities of oral lactobacilli for potential probiotic purposes. Anaerobe 2011: 17(2): 69-72.

43 Zakaria Gomaa E. Antimicrobial and anti-adhesive properties of biosurfactant produced by lactobacilli isolates, biofilm formation and aggregation ability. J Gen Appl Microbiol 2013; 59(6): 425-436.

44 Lebeer S, Verhoeven TL, Perea Vélez M et al. Impact of environmental and genetic factors on biofilm formation by the probiotic strain Lactobacillus rhamnosus GG. App Environ Microbiol 2007; 73(21): 6768-6775.

45 Muscariello L, Marino C, Capri U et al. CcpA and three newly identified proteins are involved in biofilm development in Lactobacillus plantarum. J Basic Microbiol 2013; 53(1): 62-71.

46 Kolenbrander PE, Palmer RJ Jr, Periasamy S et al. Oral multispecies biofilm development and the key role of cell-cell distance. Nat Rev Microbiol 2010; 8(7): 471-480.

47 Stamatova I, Meurman JH. Probiotics and periodontal disease. Periodontol 2000 2009; 51: 141-151.

48 Allaker RP, Douglas CW. Novel anti-microbial therapies for dental plaque-related diseases. Int J Antimicrob Agents 2009; 33(1): 8-13.

49 Näse L, Hatakka K, Savilahti E et al. Effect of long-term consumption of a probiotic bacterium, Lactobacillus rhamnosus GG, in milk on dental caries and caries risk in children. Caries Res 2001; 35(6): 412-420.

50 Karuppaiah RM, Shankar S, Raj SK et al. Evaluation of the efficacy of probiotics in plaque reduction and gingival health maintenance among school children-a randomized control trial. J Int Oral Health 2013; 5(5): 33-37.

51 Campus G, Cocco F, Carta G et al. Effect of a daily dose of Lactobacillus brevis CD2 lozenges in high caries risk schoolchildren. Clin Oral Investig 2014; 18(2): 555-561.

52 Caglar E, Sandalli N, Twetman S et al. Effect of yogurt with Bifidobacterium DN-173 010 on salivary mutans streptococci and lactobacilli in young adults. Acta Odontol Scand 2005; 63(6): 317-320.

53 Sutula J, Coulthwaite L, Thomas $L$ et al. The effect of a commercial probiotic drink on oral microbiota in healthy complete denture wearers. Microb Ecol Health Dis 2012; 23: 10.3402/mehd.v23i0.18404.

54 Madhwani T, McBain AJ. Bacteriological effects of a Lactobacillus reuteri probiotic on in vitro oral biofilms. Arch Oral Biol 2011; 56(11): 1264-1273.

55 Teanpaisan R, Piwat S, Dahlén G. Inhibitory effect of oral Lactobacillus against oral pathogens. Lett Appl Microbiol 2011; 53(4): 452-459.

56 Twetman L, Larsen U, Fiehn NE et al. Coaggregation between probiotic bacteria and caries-associated strains: an in vitro study. Acta Odontol Scand 2009; 67(5): 284-288.

57 Lang C, Böttner M, Holz C et al. Specific Lactobacillus/Mutans Streptococcus coaggregation. J Dent Res 2010; 89(2): 175-179.

58 Comelli EM, Guggenheim B, Stingele $\mathrm{F}$ et al. Selection of dairy bacterial strains as probiotics for oral health. Eur J Oral Sci 2002; 110(3): 218-224.

59 Chung J, Ha ES, Park HR et al. Isolation and characterization of Lactobacillus species inhibiting the formation of Streptococcus mutans biofilm. Oral Microbiol Immunol 2004; 19(3): 214-216.

60 Tahmourespour A, Salehi R, Kermanshahi RK et al. The anti-biofouling effect of Lactobacillus fermentum-derived biosurfactant against Streptococcus mutans. Biofouling 2011; 27(4): 385-392.

61 Söderling EM, Marttinen AM, Haukioja AL. Probiotic lactobacilli interfere with Streptococcus mutans biofilm formation in vitro. Curr Microbiol 2011; 62(2): 618-622.

62 Keller MK, Hasslöf $P$, Stecksén-Blicks C et al. Co-aggregation and growth inhibition of probiotic lactobacilli and clinical isolates of mutans streptococci: an in vitro study. Acta Odontol Scand 2011; 69(5): 263-268.

63 Tahmourespour A, Kermanshahi RK. The effect of a probiotic strain (Lactobacillus acidophilus) on the plaque formation of oral streptococci. Bosn J Basic Med Sci2011; 11(1): 37-40.

64 Marttinen AM, Haukioja AL, Keskin M et al. Effects of Lactobacillus reuteri PTA 5289 and $L$. paracasei DSMZ16671 on the adhesion and biofilm formation of Streptococcus mutans. Curr Microbiol 2013; 67(2): 193-199.

65 Pham LC, van Spanning RJ, Röling WF et al. Effects of probiotic Lactobacillus salivarius W24 on the compositional stability of oral microbial communities. Arch Oral Biol 2009; 54(2): 132-137.

66 Schwendicke F, Dörfer C, Kneist S et al. Cariogenic effects of probiotic Lactobacillus rhamnosus GG in a dental biofilm model. Caries Res 2014; 48(3): 186-192.

67 Kõll-Klais P, Mändar R, Leibur E et al. Oral lactobacilli in chronic periodontitis and periodontal health: species composition and antimicrobial activity. Oral Microbiol Immunol 2005; 20(6): 354-361.

68 Krasse P, Carlsson B, Dahl C et al. Decreased gum bleeding and reduced gingivitis by the probiotic Lactobacillus reuteri. Swed Dent J 2006; 30(2): 55-60.

69 Shimauchi H, Mayanagi G, Nakaya S et al. Improvement of periodontal condition by probiotics with Lactobacillus salivarius WB21: a randomized, double-blind, placebocontrolled study. J Clin Periodontol 2008; 35(10): 897-905.

70 Vivekananda MR, Vandana KL, Bhat KG. Effect of the probiotic Lactobacilli reuter (Prodentis) in the management of periodontal disease: a preliminary randomized clinical trial. J Oral Microbiol 2010; 2: 10.3402/jom.v2i0.5344.

71 Zhu Y, Xiao L, Shen D et al. Competition between yogurt probiotics and periodontal pathogens in vitro. Acta Odontol Scand 2010; 68(5): 261-268.

72 Shah MP, Gujjari SK, Chandrasekhar VS. Evaluation of the effect of probiotic (inersan ${ }^{\circledR}$ ) alone, combination of probiotic with doxycycline and doxycycline alone 
on aggressive periodontitis-a clinical and microbiological study. J Clin Diagn Res 2013; 7(3): 595-600.

73 Yanine N, Araya I, Brignardello-Petersen R et al. Effects of probiotics in periodontal diseases: a systematic review. Clin Oral Investig 2013; 17(7): 1627-1634.

74 Vuotto C, Barbanti F, Mastrantonio P et al. Lactobacillus brevis CD2 inhibits Prevotella melaninogenica biofilm. Oral Dis 2013; doi: 10.1111/odi.12186. [Epub ahead of print].

75 Hallström H, Lindgren S, Yucel-Lindberg $T$ et al. Effect of probiotic lozenges on inflammatory reactions and oral biofilm during experimental gingivitis. Acta Odontol Scand 2013; 71(3/4): 828-833.

76 Azevedo MS, van de Sande FH, Romano AR et al. Microcosm biofilms originating from children with different caries experience have similar cariogenicity under successive sucrose challenges. Caries Res 2011; 45(6): 510-517.

77 O'Toole PW, Cooney JC. Probiotic bacteria influence the composition and function of the intestinal microbiota. Interdiscip Perspect Infect Dis 2008; 2008: 175285.

78 Floch MH, Walker WA, Guandalini S et al. Recommendations for probiotic use-2008. J Clin Gastroenterol 2008; 42(Suppl 2): S104-S108.

79 Gionchetti P, Rizzello F, Helwig U et al. Prophylaxis of pouchitis onset with probiotic therapy: a double-blind, placebo-controlled trial. Gastroenterology 2003; 124(5): 1202-1209.

80 Mimura T, Rizzello F, Helwig U et al. Once daily high dose probiotic therapy (VSL\#3) for maintaining remission in recurrent or refractory pouchitis. Gut 2004; 53(1): 108-114.

81 Collado MC, Jalonen L, Meriluoto J et al. Protection mechanism of probiotic combination against human pathogens: in vitro adhesion to human intestinal mucus. Asia Pac J Clin Nutr 2006; 15(4): 570-575.

82 Candela M, Perna F, Carnevali $\mathrm{P}$ et al. Interaction of probiotic Lactobacillus and Bifidobacterium strains with human intestinal epithelial cells: adhesion properties, competition against enteropathogens and modulation of IL-8 production. Int J Food Microbiol 2008; 125(3): 286-292.

$83 \mathrm{Kim}$ Y, Oh S, Kim SH. Released exopolysaccharide ( $r$-EPS) produced from probiotic bacteria reduce biofilm formation of enterohemorrhagic Escherichia coli 0157:H7. Biochem Biophys Res Commun 2009; 379(2): 324-329.

84 Hancock V, Dahl M, Klemm P. Probiotic Escherichia coli strain Nissle 1917 outcompetes intestinal pathogens during biofilm formation. J Med Microbiol 2010; 59(Pt 4): 392-399.

85 Ruas-Madiedo P, Gueimonde M, Margolles A et al. Exopolysaccharides produced by probiotic strains modify the adhesion of probiotics and enteropathogens to human intestinal mucus. J Food Prot 2006; 69(8): 2011-2015.

86 Miyazaki Y, Kamiya S, Hanawa $T$ et al. Effect of probiotic bacterial strains of Lactobacillus, Bifidobacterium, and Enterococcus on enteroaggregative Escherichia coli. J Infect Chemother 2010; 16(1): 10-18.

87 Reid G, Habash M. Urogenital microflora and urinary tract infections//Tannock GW ed. Medical importance of the normal microflora. London: Kluwer, 1998: 423-440.

88 Grin PM, Kowalewska PM, Alhazzan W et al. Lactobacillus for preventing recurrent urinary tract infections in women: meta-analysis. Can J Urol 2013; 20(1): 6607-6614.

89 Kumar S, Bansal A, Chakrabarti A et al. Evaluation of efficacy of probiotics in prevention of candida colonization in a PICU-a randomized controlled trial. Crit Care Med 2013; 41(2): 565-572.

90 Stapleton AE, Au-Yeung M, Hooton TM et al. Randomized, placebo-controlled phase 2 trial of a Lactobacillus crispatus probiotic given intravaginally for prevention of recurrent urinary tract infection. Clin Infect Dis 2011; 52(10): 1212-1217.

91 MacPhee RA, Hummelen R, Bisanz JE et al. Probiotic strategies for the treatment and prevention of bacterial vaginosis. Expert Opin Pharmacother 2010; 11(18): 2985-2995.

92 Abad CL, Safdar N. The role of lactobacillus probiotics in the treatment or prevention of urogenital infections-a systematic review. J Chemother 2009; 21(3): 243-252.

93 Klebanoff SJ, Hillier SL, Eschenbach DA et al. Control of the microbial flora of the vagina by $\mathrm{H}_{2} \mathrm{O}_{2}$-generating lactobacilli. J Infect Dis 1991; 164(1): 94-100.

94 Falagas M, Betsi GI, Athanasiou S. Probiotics for the treatment of women with bacterial vaginosis. Clin Microbiol Infect 2007; 13(7): 657-664.

95 Cribby S, Taylor M, Reid G. Vaginal microbiota and the use of probiotics. Interdiscip Perspect Infect Dis 2008; 2008: 256490.

96 Homayouni A, Bastani P, Ziyadi S et al. Effects of probiotics on the recurrence of bacterial vaginosis: a review. J Low Genit Tract Dis 2014; 18(1): 79-86.

97 Ratna Sudha M, Yelikar KA, Deshpande S. Clinical study of Bacillus coagulans Unique IS-2 (ATCC PTA-11748) in the treatment of patients with bacterial vaginosis. Indian J Microbiol 2012; 52(3): 396-399.

98 Sudha MR, Maurya AK. Effect of oral supplementation of the probiotic capsule UB$01 B V$ in the treatment of patients with bacterial vaginosis. Benef Microbes 2012; 3(2): 151-155.

99 Hantoushzadeh S, Golshahi F, Javadian P et al. Comparative efficacy of probiotic yoghurt and clindamycin in treatment of bacterial vaginosis in pregnant women: a randomized clinical trial. J Matern Fetal Neonatal Med 2012; 25(7): 1021-1024.

100 Hummelen R, Changalucha J, Butamanya NL et al. Lactobacillus rhamnosus GR-1 and $L$. reuteri $\mathrm{RC}-14$ to prevent or cure bacterial vaginosis among women with $\mathrm{HIV}$. Int J Gynaecol Obstet 2010; 111(3): 245-248.

101 Hemmerling A, Harrison W, Schroeder A et al. Phase 2a study assessing colonization efficiency, safety, and acceptability of Lactobacillus crispatus CTV-05 in women with bacterial vaginosis. Sex Transm Dis 2010; 37(12): 745-750.

102 Schellenberg JJ, Dumonceaux TJ, Hill JE et al. Selection, phenotyping and identification of acid and hydrogen peroxide producing bacteria from vaginal samples of Canadian and East African women. PLoS One 2012; 7(7): e41217.
103 Parent D, Bossens M., Bayot D et al. Therapy of bacterial vaginosis using exogenouslyapplied Lactobacilli acidophili and a low dose of estriol: a placebo-controlled multicentric clinical trial. Arzneimittelforschung 1996; 46(1): 68-73.

104 Anukam KC, Osazuwa E, Osemene Gl et al. Clinical study comparing probiotic Lactobacillus GR-1 and RC-14 with metronidazole vaginal gel to treat symptomatic bacterial vaginosis. Microbes Infect 2006; 8(12/13): 2772-2776.

105 Mastromarino P. Macchia S, Meggiorini L et al. Effectiveness of Lactobacilluscontaining vaginal tablets in the treatment of symptomatic bacterial vaginosis. Clin Microbiol Infect 2009; 15(1): 67-74.

106 Anukam K, Osazuwa E, Ahonkhai I et al. Augmentation of antimicrobial metronidazole therapy of bacterial vaginosis with oral probiotic Lactobacillus rhamnosus gR-1 and Lactobacillus reuteri RC-14: randomized, double-blind, placebo controlled trial. Microbes Infect 2006; 8(6): 1450-1454.

107 Petricevic L, Witt A. The role of Lactobacillus casei rhamnosus Lcr35 in restoring the normal vaginal flora after antibiotic treatment of bacterial vaginosis. BJOG 2008; 115(11): 1369-1374.

108 Larsson PG, Stray-Pedersen B, Ryttig KR et al. Human lactobacilli as supplementation of clindamycin to patients with bacterial vaginosis reduce the recurrence rate; a 6-month, double-blind, randomized, placebo-controlled study. BMC Womens Health 2008; 8: 3.

109 Hillier SL, Krohn MA, Rabe LK et al. The normal vaginal flora, $\mathrm{H}_{2} \mathrm{O}_{2}$-producing lactobacilli, and bacterial vaginosis in pregnant women. Clin Infect Dis 1993; 16(Suppl 4): S273-S281.

110 Fredricks DN, Fiedler TL, Marrazzo JM. Molecular identification of bacteria associated with bacterial vaginosis. N Engl J Med 2005; 353(18): 1899-1911.

111 Reid G, McGroarty JA, Gil Domingue PA et al. Coaggregation of urogenital bacteria in vitro and in vivo. Curr Microbiol 1990; 20: 47-52.

112 Kaewnopparat S, Dangmanee N, Kaewnopparat $\mathrm{N}$ et al. In vitro probiotic properties of Lactobacillus fermentum SK5 isolated from vagina of a healthy woman. Anaerobe 2013; 22: 6-13.

113 Mastromarino P, Brigidi P, Macchia S et al. Characterization and selection of vaginal Lactobacillus strains for the preparation of vaginal tablets. J Appl Microbiol 2002; 93(5): 884-893.

114 Muli F, Struthers JK. Use of a continuous-culture biofilm system to study the antimicrobial susceptibilities of Gardnerella vaginalis and Lactobacillus acidophilus. Antimicrob Agents Chemother 1998; 42(6): 1428-1432.

115 Swidsinski A, Mendling W, Loening-Baucke V et al. Adherent biofilms in bacterial vaginosis. Obstet Gynecol 2005; 106(5 Pt 1): 1013-1023.

116 Patterson JL, Girerd PH, Karjane NW et al. Effect of biofilm phenotype on resistance of Gardnerella vaginalis to hydrogen peroxide and lactic acid. Am J Obstet Gynecol 2007 197(2): 170.e1-170.e7.

117 Senok AC, Verstraelen H, Temmerman M et al. Probiotics for the treatment of bacterial vaginosis. Cochrane Database Syst Rev 2009; (4): CD006289.

118 Verstraelen $\mathrm{H}$, Swidsinski A. The biofilm in bacterial vaginosis: implications for epidemiology, diagnosis and treatment. Curr Opin Infect Dis 2013; 26(1): 86-89.

119 Saunders S, Bocking A, Challis J et al. Effect of Lactobacillus challenge on Gardnerella vaginalis biofilms. Colloids Surf B Biointerfaces 2007; 55(2): 138-142.

120 McMillan A, Dell M, Zellar MP et al. Disruption of urogenital biofilms by lactobacilli. Colloids Surf B Biointerfaces 2011; 86(1): 58-64.

121 Chapman CM, Gibson GR, Rowland I. Effects of single- and multi-strain probiotics on biofilm formation and in vitro adhesion to bladder cells by urinary tract pathogens. Anaerobe 2014; 27: 71-76.

122 Borges S, Barbosa J, Silva J et al. Evaluation of characteristics of Pediococcus spp. to be used as a vaginal probiotic. J App/ Microbiol 2013; 115(2): 527-538.

123 Wong VW, Martindale RG, Longaker MT et al. From germ theory to germ therapy: skin microbiota, chronic wounds, and probiotics. Plast Reconstr Surg 2013; 132(5): 854e-886e.

124 Valdéz JC, Peral MC, Rachid M et al. Interference of Lactobacillus plantarum with Pseudomonas aeruginosa in vitro and in infected burns: the potential use of probiotics in wound treatment. Clin Microbiol Infect 2005; 11(6): 472-479.

125 Walencka E, Rózalska S, Sadowska B et al. The influence of Lactobacillus acidophilus-derived surfactants on staphylococcal adhesion and biofilm formation. Folia Microbiol Praha 2008; 53(1): 61-66.

126 Sadowska B, Walencka E, Wieckowska-Szakiel M et al. Bacteria competing with the adhesion and biofilm formation by Staphylococcus aureus. Folia Microbiol Praha 2010; 55(5): 497-501.

127 Varma P, Nisha N, Dinesh KR et al. Anti-infective properties of Lactobacillus fermentum against Staphylococcus aureus and Pseudomonas aeruginosa. J Mol Microbiol Biotechnol 2011; 20(3): 137-143.

128 Sikorska H, Smoragiewicz W. Role of probiotics in the prevention and treatment of meticillin-resistant Staphylococcus aureus infections. Int J Antimicrob Agents 2013; 42(6): 475-481

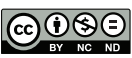

This work is licensed under a Creative Commons AttributionNonCommercial-NoDerivs 3.0 Unported License. The images or other third party material in this article are included in the article's Creative Commons license, unless indicated otherwise in the credit line; if the material is not included under the Creative Commons license, users will need to obtain permission from the license holder to reproduce the material. To view a copy of this license, visit http://creativecommons.org/licenses/ by-nc-nd/3.0/ 